\title{
Anthropometric factors have significant influence on the outcome of the GHRH-arginine test: establishment of normative data for an automated immunoassay specifically measuring 22 kDa human growth hormone
}

\author{
Timo Deutschbein', Martin Bidlingmaier', Jochen Schopohl2, \\ Christian J Strasburger ${ }^{3}$ and Stephan Petersenn ${ }^{4}$ \\ ${ }^{1}$ Department of Internal Medicine I, Division of Endocrinology and Diabetes, University Hospital \\ Würzburg, University of Würzburg, Würzburg, Germany, ${ }^{2}$ Medizinische Klinik und Poliklinik IV, \\ Klinikum der LMU München, Munich, Germany, ${ }^{3}$ Department of Medicine for Endocrinology, \\ Diabetes and Nutritional Medicine, Charité Universitätsmedizin, Campus Mitte, Berlin, Germany, and \\ ${ }^{4}$ ENDOC Center for Endocrine Tumors, Hamburg, Germany
}

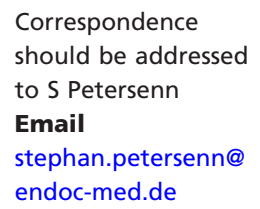

\begin{abstract}
Context: Adult growth hormone (GH) deficiency (GHD) is diagnosed by provocative testing of GH secretion. Objective: To improve the diagnostic accuracy of GH-releasing hormone (GHRH) plus arginine (GARG) testing, we evaluated the influence of age, BMI and sex and established normative data for an automatic immunoassay specifically measuring $22 \mathrm{kDa}$ human $\mathrm{GH}$.

Design/setting: Prospective multicenter study.

Participants: Eighty-seven patients with hypothalamic-pituitary disease and 200 healthy controls. Patients were classified according to the number of pituitary hormone deficiencies (PHD). GHD was assumed when $\geq 2$ PHD (in addition to $\mathrm{GH}$ ) were present ( $n=51$ ); 36 patients with $<2$ PHD were considered GH sufficient (GHS). ROC analysis identified cutoffs with $\geq 95 \%$ specificity for GHD. Controls were prospectively stratified for sex, age and BMI. Interventions: All participants received GHRH and L-arginine.

Main outcome measures: GH was measured by immunoassay (iSYS, IDS).

Results: In controls, multiple stepwise regression analysis showed that BMI $(21 \%, P<0.0001)$, sex $(20 \%, P<0.0001)$ and age $(5 \%, P<0.001)$, accounted for $46 \%$ of GH peak level variability during GARG. Comparison of peak GH during GARG (GHD vs GHS + controls) revealed an overall cutoff of $3.9 \mathrm{ng} / \mathrm{mL}$ (sensitivity $86 \%$, specificity $95 \%$ ). After adjustment for BMI and sex, optimal cutoffs (male vs female) were $6.5 \mathrm{vs} 9.7 \mathrm{ng} / \mathrm{mL}$ in lean, $3.5 \mathrm{vs} 8.5 \mathrm{ng} / \mathrm{mL}$ in overweight and $2.2 \mathrm{vs} 4.4 \mathrm{ng} / \mathrm{mL}$ in obese subjects respectively. Conclusion: BMI and sex account for most of the variability of peak GH levels during GARG. Consequently, diagnostic accuracy of the GARG test is significantly improved by use of adjusted cutoffs.
\end{abstract}

\section{Introduction}

Human growth hormone (GH) deficiency (GHD) is associated with significant morbidity and mortality $(1,2)$. For instance, large series have repeatedly shown
() 2017 European Society of Endocrinology Printed in Great Britain that hypopituitarism is generally associated with an increase in overall mortality, cardiovascular events and malignancies compared with the normal population $(3,4)$. 
Apart from that, GH-deficient individuals (especially those without replacement therapy) experience a decrease in quality of life, bone mineral density and lean body mass. Accordingly, careful diagnostic workup of suspected patients is imperatively required.

In patients with proven panhypopituitarism (i.e., at least 3 pituitary hormone deficiencies (PHD)), low levels of circulating insulin-like growth factor 1 (IGF-I), the primary mediator of the effects of $\mathrm{GH}$, are highly suspicious of somatotroph insufficiency $(1,2,5,6,7)$. However, as illustrated in current guidelines, most patients should undergo provocative testing to establish the diagnosis of GHD $(1,2,7)$. Although the insulin tolerance test (ITT) is still regarded as gold standard $(1,2,7)$, it is usually not widely applied (6). This is mainly explained by its need for serious hypoglycemia, resulting in undoubted limitations due to potential risks and several contraindications (e.g. ischemic heart disease, seizures).

As a consequence, several other dynamic endocrine tests have been evaluated to explore somatotroph function, for instance, single or combined stimulation with GH secretagogues like arginine, clonidine, GH-releasing hormone (GHRH), GH-releasing peptide 6 (GHRP6), glucagon and levodopa (L-DOPA) (5, 6, 8, 9, 10, 11, 12, $13,14,15,16)$. Some of these tests have severe limitations (e.g. impaired sensitivity, high costs); however, the GHRH plus arginine (GARG) test has repeatedly been described as a good alternative to the ITT $(1,2,5,7,17,18,19)$. Of note, as GH responses during the GARG test decline by increasing body mass index (BMI) and age, adjusted cutoffs have been proposed $(13,14)$. Unfortunately, however, the weighted influence of these two variables (either alone or in combination) as well as the influence of sex have not been adequately evaluated so far.

Recently, desirable characteristics for GH measurement have been stated by a consensus recommendation (20). These aspects are fulfilled by a modern automated immunoassay specifically measuring $22 \mathrm{kDa}$ human GH (21).

Our study was therefore designed to empirically define reference data for stimulated $\mathrm{GH}$ responses in adults, improving the diagnostic accuracy of the GARG test using the formerly mentioned immunoassay. We investigated a well-defined cohort of healthy subjects who were prospectively recruited in such a way that anthropometric factors (e.g. age, BMI, and sex) were reflected on a sufficiently weighted basis. Multiple stepwise regression analysis was performed to identify their potential influence on GH levels. To identify cutoffs with at least 95\% specificity for GHD, patients suffering from hypothalamic-pituitary diseases were included, using the degree of pituitary impairment as gold standard and applying receiver-operating characteristics (ROC) analysis.

\section{Subjects and methods}

\section{Subjects}

The study protocol was approved by the local ethics committee (approval number: 04-2390), and all study participants provided written informed consent.

\section{Controls}

Two hundred healthy subjects were recruited from the general population. None of these subjects had a history of severe and/or chronic illness (especially of endocrine origin). Females on hormonal contraceptives or hormone replacement therapy as well as all subjects who were currently or in the prior months taking drugs known to interfere with the synthesis or metabolism of endocrine parameters were excluded. To evaluate the influence of anthropometric variables, subjects were prospectively stratified for sex (male vs female), age (18-30 years, 3150 years and $>50$ years $)$ and $\mathrm{BMI}\left(<25 \mathrm{~kg} / \mathrm{m}^{2}, 25-30 \mathrm{~kg} / \mathrm{m}^{2}\right.$ and $>30 \mathrm{~kg} / \mathrm{m}^{2}$ ). Study participants were selected in such a way that each group comprised at least 10 subjects (i.e. 10 males aged $18-30$ years with a BMI $<25 \mathrm{~kg} / \mathrm{m}^{2}$; 10 males aged $31-50$ years with a BMI $<25 \mathrm{~kg} / \mathrm{m}^{2} ; 10$ males older than 50 years with a BMI $<25 \mathrm{~kg} / \mathrm{m}^{2}$; and so on). Unfortunately, one control subject was misclassified at screening. Therefore, the group 'females, 31-50 years, BMI $>30 \mathrm{~kg} / \mathrm{m}^{2 \prime}$ contains only 9 subjects.

\section{Patients}

Eighty-seven patients with hypothalamic-pituitary diseases were enrolled (details are given in Table 1). Subjects who had already been surgically treated had their first regular endocrine workup at least three months after surgery. Two of the 87 patients (2.3\%) had been treated by irradiation 1 and 9 years prior to GARG testing respectively. Both of them had insufficiencies of all pituitary axes at the time of GARG testing. Patients with suspected or proven pituitary insufficiency received hormonal replacement therapy (i.e. glucocorticoids, gonadal steroids, thyroxine and desmopressin) with the exception of growth hormone. In detail, 45 patients with corticotropic insufficiency received hydrocortisone orally 
Table 1 Clinical characteristics of patients.

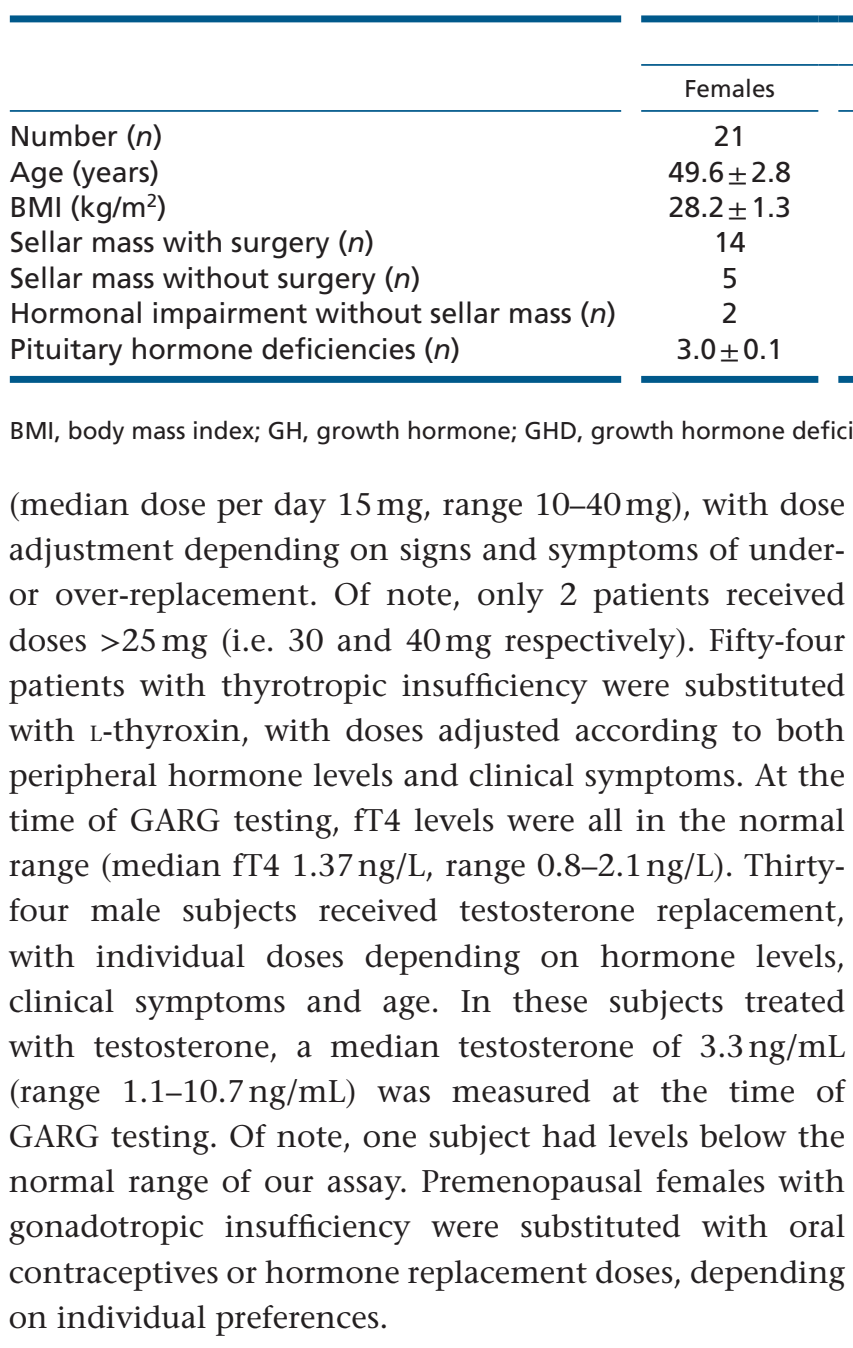

\section{Methods}

\section{Collection of samples}

Blood sampling was generally performed between 08:00 h and 10:00 h after an overnight fast. Samples were taken by venipuncture of a forearm vein. If measurement was not performed directly afterward, blood samples were centrifuged and stored at $-20^{\circ} \mathrm{C}$.

\section{Dynamic testing procedures for the assessment of somatotroph function}

During GARG, patients received GHRH $(1 \mu \mathrm{g} / \mathrm{kg})$ by an i.v. bolus, followed by a 30-min i.v. infusion of L-arginine $(30 \mathrm{~g})$. Blood samples were taken at 0, 30, 45, 60, 90 and $120 \mathrm{~min}$. In the initial phase of the study, we also evaluated the diagnostic performance of the ITT. In 44 patients, administration of insulin $(0.10-0.15 \mathrm{U} / \mathrm{kg})$ was followed by blood sampling at $0,15,30,45,60,90$ and $120 \mathrm{~min}$. Both target serum glucose of $\leq 40 \mathrm{mg} / \mathrm{dL}$ and symptoms of neuroglucopenia were required as indicators of sufficient stress response.

\section{Additional hormonal workup}

In 44 patients, corticotroph function was investigated by cortisol peak levels during ITT. In the remaining patients, adrenal insufficiency was established either by repeatedly low early morning serum cortisol or by corticotropin-releasing hormone (CRH) testing. Parameters used for characterization of gonadotroph function were testosterone, luteinizing hormone (LH) and follicle-stimulating hormone (FSH) (males); history of regular menses along with estradiol, progesterone, LH and FSH (premenopausal females); LH and FSH only (postmenopausal females). Selected cases also underwent gonadotropin-releasing hormone (GnRH) testing. Thyrotroph function was assessed by thyroid-stimulating hormone (TSH) and peripheral thyroid hormones, with additional thyreotropin-releasing hormone (TRH) testing in some cases.

\section{Interpretation of endocrine parameters}

Similar to the approach published by Biller et al., reduced responses to testing of the corticotropic, gonadotropic and thyrotropic axes as well as evidence of diabetes insipidus were separately considered as PHD (5). Therefore, the possible range for grading the severity of PHD was one to four, with two or more insufficiencies (i.e., other than GHD) being classified as multiple PHD (MPHD). As already outlined by Biller et al., prior studies have shown that the latter group has an approximately $90 \%$ chance of having severe GHD $(22,23)$. Patients with less than 2 PHD were classified as GH sufficient (GHS). 


\section{Measurement of samples and calculation of estimates}

Serum GH was measured by an automated immunoassay (iSYS, Immunodiagnostic Systems (IDS), Boldon, UK) calibrated against the latest International Standard code 98/574 (NIBSC, Hertfordshire, UK). Validation and characterization of the assay had been performed according to recommendations by the clinical laboratory standards institute (CLSI), and results were published in detail elsewhere (21). The epitopes of the monoclonal antibodies used in this assay ensure specific measurement of the $22 \mathrm{kDa}$ isoform of GH. Performance of the assay during the study was routinely monitored by internal quality control, longitudinal assessment of serum pools and participation in external quality control programs.

\section{Statistical analysis}

Multiple stepwise regression analysis was performed with the following covariates in the model: age, BMI and sex. Groups were compared by Mann-Whitney test, where appropriate. The diagnostic accuracy of GARG and ITT was determined by ROC analysis and its corresponding area under the curve (AUC). That way, we aimed to establish cutoffs (with a specificity of $\geq 95 \%$ for GHD) under special consideration of the most relevant anthropometric factors. Statistical significance was taken as $P<0.05$. Results are expressed as the mean \pm standard error of the mean (s.e.M.) unless otherwise stated. GraphPad Prism 6.0 software (GraphPad Software) and JMP10 (SAS Institute Inc., Cary, NC, USA) were used for statistical calculations.

\section{Results}

\section{Influence of age, BMI and sex on GH peak levels in healthy subjects}

The control group comprised 200 healthy subjects: 102 males (age $39.7 \pm 1.5$ years (range 19-75 years), BMI $27.8 \pm 0.5 \mathrm{~kg} / \mathrm{m}^{2}$ (range $\left.19.0-40.9 \mathrm{~kg} / \mathrm{m}^{2}\right)$ ) and 98 females (age 39.2 \pm 1.3 years (range 18-68 years), BMI $27.7 \pm 0.6 \mathrm{~kg} / \mathrm{m}^{2}$ (range $\left.18.0-46.5 \mathrm{~kg} / \mathrm{m}^{2}\right)$ ). If male and female controls were compared, no significant differences between mean age and mean BMI were detected. Multiple stepwise regression analysis revealed that both BMI (21\%, $P<0.0001)$ and sex $(20 \%, P<0.0001)$ accounted for most of the variability of GH peak levels during the GARG test, whereas the influence of age $(5 \%, P<0.001)$ was much less dominant. Mean peak GH levels were significantly higher in females compared with males $(27.4 \pm 1.73 \mathrm{ng} \mathrm{mL}$ vs
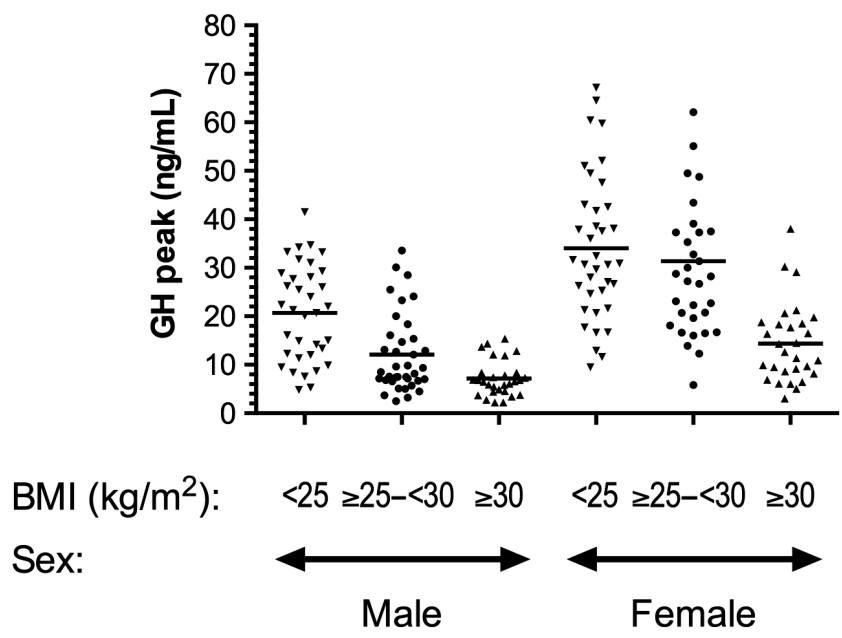

Figure 1

Peak GH levels during the GARG test in 200 healthy subjects, stratified by sex and BMI. Dark lines represent the means for each group. $\mathrm{GH}$, growth hormone.

$13.7 \pm 0.95 \mathrm{ng} / \mathrm{mL}, \quad P<0.0001)$ and higher in lean $(34.1 \pm 2.46 \mathrm{ng} / \mathrm{mL}$ in females vs $20.7 \pm 1.67 \mathrm{ng} / \mathrm{mL}$ in males, $P<0.0001)$ compared with overweight $(31.4 \pm 3.38 \mathrm{ng} / \mathrm{mL}$ in females vs $12.1 \pm 1.34 \mathrm{ng} / \mathrm{mL}$ in males, $P<0.0001)$ and obese subjects $(14.4 \pm 1.52 \mathrm{ng} / \mathrm{mL}$ in females vs $7.19 \pm 0.68 \mathrm{ng} / \mathrm{mL}$ in males, $P<0.0001$ ) (Fig. 1 ).

As changes in sex hormones during menopause could be interfering and potentially explain some of the sex differences in peak GH levels, we performed additional analyses in 139 healthy subjects (age 18-50 years) of whom females were presumably premenopausal and 60 subjects (age $>50$ years) of whom females were presumably menopausal. Peak GH remained significantly higher in 67 females between 18 and 50 years of age compared with 72 males $(29.8 \pm 2.19 \mathrm{ng} / \mathrm{mL}$ in females vs $15.2 \pm 1.14 \mathrm{ng} / \mathrm{mL}$ in males, $P<0.0001)$, and in 31 females who were $>50$ years old compared with 29 males $(22.1 \pm 2.5 \mathrm{ng} / \mathrm{mL}$ in females vs $9.8 \pm 1.52 \mathrm{ng} / \mathrm{mL}$ in males, $P<0.0001)$.

\section{Patient cohort}

Out of the 87 subjects with hypothalamic-pituitary diseases (51 males, 36 females; age $48.7 \pm 1.5$ years (range 18-74 years), BMI $27.6 \pm 0.6 \mathrm{~kg} / \mathrm{m}^{2}$ (range $\left.\left.16.7-43.2 \mathrm{~kg} / \mathrm{m}^{2}\right)\right), \quad 17$ patients were investigated specifically due to suspicion of pituitary insufficiency (7x clinical symptoms; $3 \times$ traumatic brain injury; $2 \times$ congenital panhypopituitarism; each $1 \times$ cerebral lymphoma after cranial radiotherapy, congenital isolated growth hormone deficiency, empty sella syndrome, 
Table 2 Sex-specific BMI-dependent cutoffs in the combined arginine-GHRH test for GH as measured by the IDS iSYS assay with a specificity of $\geq 95 \%$ for GHD.

\begin{tabular}{|c|c|c|c|c|c|c|c|}
\hline & \multirow[b]{2}{*}{ Overall } & \multicolumn{3}{|c|}{ Males } & \multicolumn{3}{|c|}{ Females } \\
\hline & & $\begin{array}{c}\text { Lean } \\
\left(\mathrm{BMI}<25 \mathrm{~kg} / \mathrm{m}^{2}\right) \\
\end{array}$ & $\begin{array}{c}\text { Overweight } \\
\left(\mathrm{BMI} \geq 25-<30 \mathrm{~kg} / \mathrm{m}^{2}\right)\end{array}$ & $\begin{array}{c}\text { Obese } \\
\left(\mathrm{BMI} \geq 30 \mathrm{~kg} / \mathrm{m}^{2}\right)\end{array}$ & $\begin{array}{c}\text { Lean } \\
\left(\mathrm{BMI}<25 \mathrm{~kg} / \mathrm{m}^{2}\right) \\
\end{array}$ & $\begin{array}{c}\text { Overweight } \\
\left(\mathrm{BMI} \geq 25-<30 \mathrm{~kg} / \mathrm{m}^{2}\right)\end{array}$ & $\begin{array}{c}\text { Obese } \\
\left(\text { BMI } \geq 30 \mathrm{~kg} / \mathrm{m}^{2}\right)\end{array}$ \\
\hline $\begin{array}{l}\text { Cutoff } \\
(\mathrm{ng} / \mathrm{mL})\end{array}$ & 3.9 & 6.5 & 3.5 & 2.2 & 9.7 & 8.5 & 4.4 \\
\hline $\begin{array}{l}\text { Sensitivity } \\
(\%)\end{array}$ & 86 & 100 & 92 & 91 & 83 & 100 & 67 \\
\hline $\begin{array}{l}\text { Specificity } \\
(\%)\end{array}$ & 95 & 95 & 96 & 97 & 96 & 97 & 97 \\
\hline ROC AUC & 0.97 & 1.00 & 0.99 & 0.99 & 0.97 & 1.00 & 0.95 \\
\hline$P$ value & $<0.0001$ & $<0.0001$ & $<0.0001$ & $<0.0001$ & $<0.0005$ & $<0.0001$ & $<0.001$ \\
\hline
\end{tabular}

$\mathrm{BMI}$, body mass index; GH, growth hormone; GHD, growth hormone deficiency; ROC, receiver-operating characteristics; AUC, area under the curve.

Sheehan's syndrome and subarachnoid hemorrhage), whereas the remaining 70 patients had been tested because of proven sellar masses. Forty-seven of the latter subjects had already been surgically treated (30x nonfunctioning pituitary adenoma; $8 \times$ ACTH secreting pituitary adenoma; $3 \times$ meningioma; $2 \times$ prolactinoma; each $1 \times$ arachnoid cyst, colloid cyst, craniopharyngioma and growth hormonesecreting pituitary adenoma), whereas 23 patients had not yet been operated ( $8 \times$ craniopharyngioma; $7 \times$ nonfunctioning pituitary adenoma; $4 \times$ prolactinoma; $2 \times$ meningioma; each $1 \times$ astrocytoma and suprasellar myxoid chondroma). Fifty-one of the 87 patients had MPHD as defined previously and were therefore assumed GHD, whereas 36 patients had $\leq 1$ PHD and were therefore considered to be GHS. The median number of PHD was 3 in the GHD and 1 in the GHS group. Clinical characteristics of patients are provided in Table 1 .

\section{Establishment of new cutoffs for peak GH levels during the GHRH plus arginine test by comparison of growth hormone-deficient patients and control subjects}

Considering the significant influence of BMI and sex for the GARG in normal subjects, we aimed to establish diagnostic cutoffs that were adjusted accordingly. Comparison of peak GH levels during the GARG test of patients with MPHD to those of a control group (consisting of patients with PHD $<2$ and healthy subjects) allowed calculation of cutoffs for peak GH (either as an overall threshold or as BMI-dependent thresholds with at least 95\% specificity for GHD, with the latter being separately provided for both sexes). As shown in Table 2 as well as in Fig. 2, the overall cutoff for both sexes was $3.9 \mathrm{ng} / \mathrm{mL}$ (sensitivity $86 \%$ (95\% confidence interval (CI) 74-94\%), specificity 95\% (95\% CI 92-98\%)); the BMI-adjusted thresholds were $6.5,3.5$ and $2.2 \mathrm{ng} / \mathrm{mL}$ for males and 9.7, 8.5, and $4.4 \mathrm{ng} / \mathrm{mL}$ for females (always for lean, overweight and obese subjects respectively). Of note, our group of patients with less than 2 PHD may contain some subjects with isolated GHD, which could influence our analysis. We therefore repeated our ROC analysis focusing on patients with MPHD in comparison to healthy
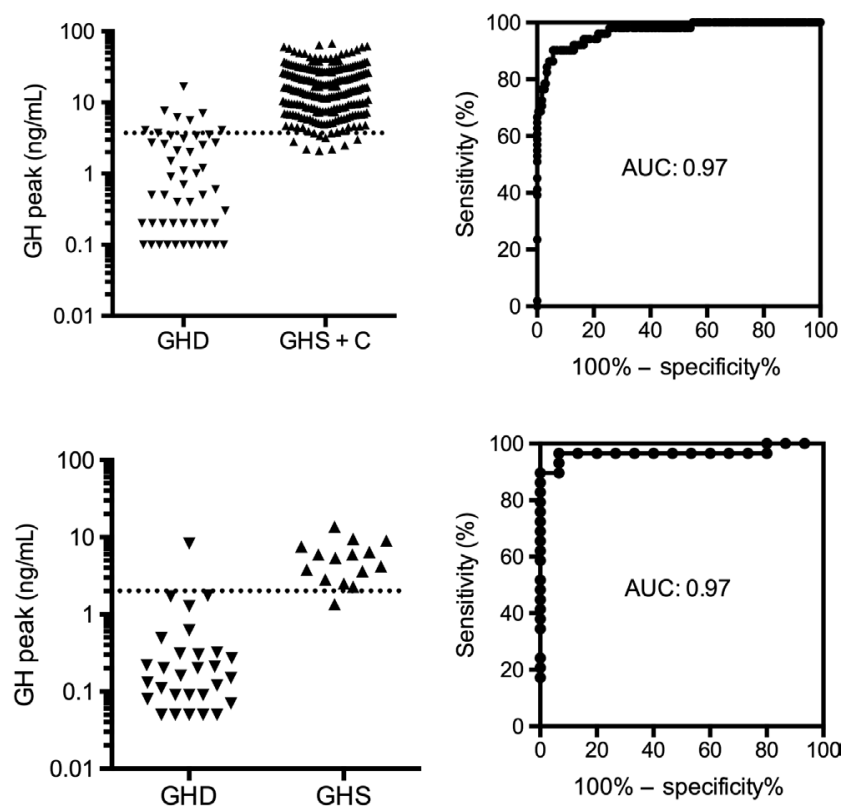

Figure 2

Peak GH levels and corresponding ROC curves during (upper panel) GARG test and (lower panel) ITT. The broken lines indicate the overall $\mathrm{GH}$ cutoff $(3.9 \mathrm{ng} / \mathrm{mL}$ during the GARG test, $2 \mathrm{ng} / \mathrm{mL}$ during the ITT). AUC, area under the curve; $C$, healthy subjects; GARG, growth hormone-releasing hormone plus arginine; $\mathrm{GH}$, growth hormone; GHD, growth hormone deficiency; GHS, growth hormone sufficiency; ITT, insulin tolerance test. 
controls alone. Interestingly, the results were very similar: the overall cutoff for both sexes was $3.8 \mathrm{ng} / \mathrm{mL}$ (sensitivity 86\% (95\% CI 73-94\%), specificity 95\% (95\% CI 92-98\%)).

\section{Diagnostic performance of the insulin tolerance test}

Forty-four of the 87 patients (51\%) also underwent an ITT as additional reference test. ROC analysis suggested a GH cutoff of $2.0 \mathrm{ng} / \mathrm{mL}$ that categorized 29 patients as GHD and 15 patients as GHS (sensitivity 95\% and specificity 93\%). Hence, two cases were discordant to the classification by the degree of pituitary impairment (i.e., 1 GHS patient with 3 PHD and 1 GHD patient with 0 PHD).

If the 'classical' GH cutoff of $3.0 \mathrm{ng} / \mathrm{mL}$ was applied, 32 patients were regarded as GHD and 12 patients as GHS. Using ITT, 1 individual with $\geq 2$ PHD was considered GHS, whereas 4 individuals (each with 0 PHD) were classified as GHD. As a result, sensitivity remained at $95 \%$, whereas specificity dropped to $73 \%$.

\section{Discussion}

The current study established reference data for peak GH during the GARG test, using a modern automated immunoassay, which had been developed in compliance with recent consensus guidelines and specifically measures the $22 \mathrm{kDa}$ isoform of human $\mathrm{GH}$. To establish diagnostic cutoffs, prospectively recruited subjects from the general population underwent careful questioning and examination, thereby including only well-defined healthy controls. Multiple stepwise regression analysis was performed to determine the influence of various anthropometric variables on GH, identifying BMI and sex as the most relevant parameters. Consequently, adjusted cutoffs with at least 95\% specificity for GHD were derived from ROC analysis, investigating patients with proven hypothalamic-pituitary diseases (using the number of PHD as gold standard).

Although measurement of GH and IGF-I is a cornerstone of the diagnostic and therapeutic monitoring of diseases associated with an impaired somatotroph function, considerable difficulties exist with respect to the comparability of currently available measurement techniques and their respective analytical performance $(20,24)$. Therefore, the recent consensus guidelines on $\mathrm{GH}$ assay performance have called for method-specific cutoffs for each GH assay (20). Noteworthy, the need to establish cutoffs not only for each individual hormone and dynamic test but also for each of the different measurement techniques used to quantify the hormones has already been demonstrated for other hormones (25). The cutoff data presented here apply for the specific GH assay used, and conversion of data obtained by one GH assay into another GH assay is explicitly discouraged by the guidelines. However, especially in a pediatric population where ethical reasons might prohibit the re-establishment of cutoffs with each new assay, it is helpful to know that a recent publication has proposed formulas allowing a comparison of GH concentrations obtained by the IDS iSYS GH assay to other commercially available immunoassays (26). To date, robust reference ranges for other parameters associated with somatotroph function (IGF1 and IGF-BP3) measured on the same analytical platform have already been established $(27,28,29)$, but the present study is the first to provide assay-specific cutoffs for GH stimulation tests for this assay.

In patients with suspicion for GHD, current guidelines regard testing with well-established dynamic endocrine procedures as mandatory $(1,2,7)$. Over the last years, the GARG test has repeatedly been described as a reliable alternative to the traditional gold standard ITT, which is nowadays regarded as unpleasant, cumbersome and potentially life-threatening $(1,2,5,7,17,18,19)$.

Of note, a significant relationship between anthropometric parameters and GH levels during dynamic endocrine testing has been described, e.g. for the oral glucose tolerance test (30) and the GARG test $(5,13,14)$. With respect to the latter test, BMI-dependent cutoffs for peak GH have been suggested, mainly to overcome overlapping $\mathrm{GH}$ responses between GHD and obese patients $(13,14)$. We also identified BMI as the most relevant confounder in our current analysis, accounting for $21 \%$ of the variability of peak GH during the GARG test. Unfortunately, though, a further analysis of the underlying pathophysiological mechanism for this finding was not feasible, as additional parameters of metabolic disturbance (e.g. visceral fat mass, visceral fat mass, fasting insulin levels and waist circumference) were not routinely determined.

Interestingly, multiple stepwise regression analysis revealed that sex had a very comparable effect to BMI (i.e., accounting for $20 \%$ of peak GH variability). We therefore decided to establish combined BMI- and sexadjusted cutoffs rather than various cutoffs only adjusted for one of these potential confounders.

It has to be pointed out that these newly established thresholds were markedly lower in males $(6.5,3.5$ and $2.2 \mathrm{ng} / \mathrm{mL}$ for lean, overweight and obese subjects) than those in females $(9.7,8.5$ and $4.4 \mathrm{ng} / \mathrm{mL}$ ) and not well 
comparable to BMI-dependent thresholds published by Corneli et al. (i.e., $11.5,8.0$ and $4.2 \mathrm{ng} / \mathrm{mL}$ for males and females combined) or Colao et al. (who did not observe a gender effect and provided age-specific cutoffs instead, ranging from 12.0 to $21.5 \mathrm{ng} / \mathrm{mL}, 11.1$ to $16.5 \mathrm{ng} / \mathrm{mL}$ and 4.0 to $15.0 \mathrm{ng} / \mathrm{mL}$ respectively) (threshold values in both studies always given for lean, overweight and obese subjects) $(13,14)$. As discussed previously, variations in the assay methods used in the former studies certainly contribute to the differences in concentrations reported. However, these differences might also point to other confounders in the respective cohorts investigated (e.g. anthropometric factors other than BMI, which appears to have a relatively robust inverse correlation to $\mathrm{GH})$. With respect to age, some groups have reported that peak GH levels during the GARG test were substantially decreasing in the elderly (14), whereas others did not observe such a decline (addressing either the GARG test only (31) or several GH stimulation tests at the same time) (5). Divergent results have also been published for the role of sex, with reports ranging from no $(14,31)$ to a significant (5) impact on peak GH levels during the GARG test. Our study confirms the influence of sex, which appears to be plausible in view of the known, significantly stimulating effect of estradiol on GH secretion $(32,33)$. Our current multiple stepwise regression analysis and the results published by Biller et al. (5) strongly suggest that sex may have a more dominant effect on GH peak levels than age, with GH peak values more than twice as high in females compared with males. As a result, we believe that the use of cutoffs adjusted for BMI and sex could be a reasonable approach to improve diagnostic accuracy.

Our study has limitations. For instance, although we included a comparably large cohort of healthy subjects, our patient cohort was smaller than that in some of the previous studies on this topic. Although the rarity of GH-related disorders needs to be considered, larger investigations are certainly needed to better define the impact of sex and BMI on patients. Such studies should ideally be designed as large prospective multicenter studies to also account for other potential confounders. Nevertheless, all of our patients were carefully clinically reviewed, with special emphasis on symptoms and biochemical signs suggestive of (additional) PHD. In line with current recommendations, we strongly believe that this approach allows for a reliable identification of hypopituitarism. This assumption is also supported by the good agreement between clinical annotations and the corresponding ITT in a subgroup of the patients. Another drawback of our current analysis is that previous studies of GARG have demonstrated limited sensitivity to diagnose GHD in patients with prior irradiation $(34,35)$. It has been speculated that the GH response to arginine may be somehow resistant to the effects of radiation (36). As our patient cohort contained only 2 patients after radiation, we believe that the results are not biased by this treatment, but like to emphasize that the results may not apply to patients after cranial irradiation. Furthermore, the GARG test itself has certain pitfalls. For instance, GHRH is not easily available, making the test quite cumbersome. Moreover, as many potential confounders need to be considered, different cutoffs values have to be memorized (which are only valid for the specific assay applied). Consequently, each center needs to establish its own normative data.

In conclusion, here we provide method-specific cutoffs for a new automated immunoassay specifically measuring the $22 \mathrm{kDa}$ isoform of human GH. Furthermore, we defined the effects of anthropometric factors on peak GH levels during the GARG test. We demonstrated that BMI and sex account for most of the variability in peak $\mathrm{GH}$, thereby having important impact on the diagnosis of GHD. Consequently, the diagnostic accuracy of the GARG test is significantly improved by application of BMI- and sex-adjusted cutoffs.

\section{Declaration of interest}

The authors declare that there is no conflict of interest that could be perceived as prejudicing the impartiality of the research reported. Stephan Petersenn has received research support from IDS, and Martin Bidlingmaier has received research support and consultancy fees from IDS.

\section{Funding}

Timo Deutschbein received a grant from the Interdisciplinary Center for Clinical Research (IZKF) of the University of Würzburg (grant number Z-2/57).

\section{Author contribution statement}

Timo Deutschbein and Stephan Petersenn conducted the statistical analyses. All authors collected samples, provided patient data and wrote the manuscript.

\section{References}

1 Cook DM, Yuen KC, Biller BM, Kemp SF, Vance ML \& American Association of Clinical Endocrinologists. American Association of Clinical Endocrinologists medical guidelines for clinical practice for growth hormone use in growth hormone-deficient adults and transition patients - 2009 update: executive summary of recommendations. Endocrine Practice 200915 580-586. (doi:10.4158/ EP.15.6.580)

2 Molitch ME, Clemmons DR, Malozowski S, Merriam GR, Vance ML $\&$ Endocrine Society. Evaluation and treatment of adult growth 
hormone deficiency: an Endocrine Society clinical practice guideline. Journal of Clinical Endocrinology and Metabolism 201196 1587-1609. (doi:10.1210/jc.2011-0179)

3 Bates AS, Van't Hof W, Jones PJ \& Clayton RN. The effect of hypopituitarism on life expectancy. Journal of Clinical Endocrinology and Metabolism 199681 1169-1172. (doi:10.1210/jcem.81.3.8772595)

4 Svensson J, Bengtsson BA, Rosén T, Odén A \& Johannsson G. Malignant disease and cardiovascular morbidity in hypopituitary adults with or without growth hormone replacement therapy. Journal of Clinical Endocrinology and Metabolism 200489 3306-3312. (doi:10.1210/jc.2003-031601)

5 Biller BM, Samuels MH, Zagar A, Cook DM, Arafah BM, Bonert V, Stavrou S, Kleinberg DL, Chipman JJ \& Hartman ML. Sensitivity and specificity of six tests for the diagnosis of adult GH deficiency. Journal of Clinical Endocrinology and Metabolism 200287 2067-2079. (doi:10.1210/jcem.87.5.8509)

6 Hartman ML, Crowe BJ, Biller BMK, Ho KKY, Clemmons DR, Chipman JJ, HyposCCS Advisory Board \& U.S. HypoCCS Study Group. Which patients do not require a growth hormone (GH) stimulation test for the diagnosis of adult GH deficiency? Journal of Clinical Endocrinology and Metabolism 200287 477-485. (doi:10.1210/ jcem.87.2.8216)

7 Ho KK \& 2007 GH Deficiency Consensus Workshop Participants. Consensus guidelines for the diagnosis and treatment of adults with GH deficiency II: a statement of the GH Research Society in association with the European Society for Pediatric Endocrinology, Lawson Wilkins Society, European Society of Endocrinology, Japan Endocrine Society, and Endocrine Society of Australia. European Journal of Endocrinology 2007157 695-700. (doi:10.1530/EJE-07-0631)

8 Rahim A, Toogood AA \& Shalet SM. The assessment of growth hormone status in normal young adult males using a variety of provocative agents. Clinical Endocrinology 199645 557-562. (doi:10.1046/j.1365-2265.1996.00855.x)

9 Aimaretti G, Baffoni C, DiVito L, Bellone S, Grottoli S, Maccario M, Arvat E, Camanni F \& Ghigo E. Comparisons among old and new provocative tests of $\mathrm{GH}$ secretion in 178 normal adults. European Journal of Endocrinology 2000142 347-352. (doi:10.1530/ eje.0.1420347)

10 Hoeck HC, Vestergaard P, Jakobsen PE, Falhof J \& Laurberg P. Diagnosis of growth hormone (GH) deficiency in adults with hypothalamic-pituitary disorders: comparison of test results using pyridostigmine plus GH-releasing hormone (GHRH), clonidine plus GHRH, and insulin-induced hypoglycemia as GH secretagogues. Journal of Clinical Endocrinology and Metabolism 200085 1467-1472. (doi:10.1210/jcem.85.4.6538)

11 Popovic V, Leal A, Micic D, Koppeschaar HP, Torres E, Paramo C, Obradovic S, Dieguez C \& Casanueva FF. GH-releasing hormone and GH-releasing peptide- 6 for diagnostic testing in GH-deficient adults. Lancet 2000356 1137-1142. (doi:10.1016/S0140-6736(00)02755-0)

12 Leong KS, Walker AB, Martin I, Wile D, Wilding J \& MacFarlane IA. An audit of 500 subcutaneous glucagon stimulation tests to assess growth hormone and ACTH secretion in patients with hypothalamicpituitary disease. Clinical Endocrinology 200154 463-468. (doi:10.1046/j.1365-2265.2001.01169.x)

13 Corneli G, Di Somma C, Baldelli R, Rovere S, Gasco V, Croce CG, Grottoli S, Maccario M, Colao A, Lombardi G et al. The cut-off limits of the $\mathrm{GH}$ response to $\mathrm{GH}$-releasing hormone-arginine test related to body mass index. European Journal of Endocrinology 2005153 257-264. (doi:10.1530/eje.1.01967)

14 Colao A, Di Somma C, Savastano S, Rota F, Savanelli MC, Aimaretti G \& Lombardi G. A reappraisal of diagnosing GH deficiency in adults: role of gender, age, waist circumference, and body mass index. Journal of Clinical Endocrinology and Metabolism 200994 4414-4422. (doi:10.1210/jc.2009-1134)

15 Alaioubi B, Mann K \& Petersenn S. Diagnosis of adrenal insufficiency using the GHRP-6 test: comparison with the insulin tolerance test in patients with hypothalamic-pituitary-adrenal disease. Hormone and Metabolic Research 201042 198-203. (doi:10.1055/s-0029-1243184)

16 Berg C, Meinel T, Lahner H, Yuece A, Mann K \& Petersenn S. Diagnostic utility of the glucagon stimulation test in comparison to the insulin tolerance test in patients following pituitary surgery. European Journal of Endocrinology 2010162 477-482. (doi:10.1530/EJE09-0824)

17 Chanson P, Cailleux-Bounacer A, Kuhn JM, Weryha G, Chabre O, Borson-Chazot F, Dubois S, Vincent-Dejean C, Brue T, Fedou C et al. Comparative validation of the growth hormone-releasing hormone and arginine test for the diagnosis of adult growth hormone deficiency using a growth hormone assay conforming to recent international recommendations. Journal of Clinical Endocrinology and Metabolism 201095 3684-3692. (doi:10.1210/jc.2010-0295)

18 Markkanen HM, Pekkarinen T, Välimäki MJ, Alfthan H, Hämäläinen E \& Stenman UH. Comparison of two growth hormone stimulation tests and their cut-off limits in healthy adults at an outpatient clinic. Growth Hormone and IGF Research 201323 165-169. (doi:10.1016/j. ghir.2013.06.002)

19 Andersen M. The robustness of diagnostic tests for GH deficiency in adults. Growth Hormone and IGF Research 201525 108-114. (doi:10.1016/j.ghir.2015.03.001)

20 Clemmons DR. Consensus statement on the standardization and evaluation of growth hormone and insulin-like growth factor assays. Clinical Chemistry 201157 555-559. (doi:10.1373/ clinchem.2010.150631)

21 Manolopoulou J, Alami Y, Petersenn S, Schopohl J, Wu Z, Strasburger $\mathrm{J} \&$ Bidlingmaier M. Automated 22-kDa growth hormone-specific assay without interference from pegvisomant. Clinical Chemistry 2012 58 1446-1456. (doi:10.1373/clinchem.2012.188128)

22 Toogood AA, Beardwell CG \& Shalet SM. The severity of growth hormone deficiency in adults with pituitary disease is related to the degree of hypopituitarism. Clinical Endocrinology 199441 511-516. (doi:10.1111/j.1365-2265.1994.tb02583.x)

23 Bates AS, Evans AJ \& Clayton RN. Assessment of GH status in adults with GH deficiency using serum growth hormone, serum insulinlike growth factor-I and urinary growth hormone excretion. Clinical Endocrinology 199542 425-430. (doi:10.1111/j.1365-2265.1995. tb02652.x)

24 Bidlingmaier M \& Freda PU. Measurement of human growth hormone by immunoassays: current status, unsolved problems and clinical consequences. Growth Hormone and IGF Research 200920 19-25. (doi:10.1016/j.ghir.2009.09.005)

25 Deutschbein T \& Petersenn S. Screening for Cushing's syndrome: new immunoassays require adequate normative data. Hormone and Metabolic Research 201345 118-123. (doi:10.1055/s-0032-1331745)

26 Müller A, Scholz M, Blankenstein O, Binder G, Pfäffle R, Körner A, Kiess W, Heider A, Bidlingmaier M, Thiery J et al. Harmonization of growth hormone measurements with different immunoassays by data adjustment. Clinical Chemistry and Laboratory Medicine 201149 1135-1142. (doi:10.1515/cclm.2011.201)

27 Bidlingmaier M, Friedrich N, Emeny RT, Spranger J, Wolthers OD, Roswall J, Körner A, Obermayer-Pietsch B, Hübener C, Dahlgren $\mathrm{J}$ et al. Reference intervals for insulin-like growth factor-1 (igf-i) from birth to senescence: results from a multicenter study using a new automated chemiluminescence IGF-I immunoassay conforming to recent international recommendations. Journal of Clinical Endocrinology and Metabolism 201499 1712-1721. (doi:10.1210/ jc.2013-3059)

28 Friedrich N, Wolthers OD, Arafat AM, Emeny RT, Spranger J, Roswall J, Kratzsch J, Grabe HJ, Hübener C, Pfeiffer AF et al. Age and sex specific reference intervals across lifespan for insulin-like growth factor binding protein 3 (IGFBP-3) and the IGF-I/IGFBP-3 ratio measured by new automated chemiluminescence assays. Journal of Clinical Endocrinology and Metabolism 201499 1675-1686. (doi:10.1210/jc.2013-3060) 
29 Wagner IV, Paetzold C, Gausche R, Vogel M, Koerner A, Thiery J, Arsene CG, Henrion A, Guettler B, Keller E et al. Clinical evidencebased cutoff limits for GH stimulation tests in children with a backup of results with reference to mass spectrometry. European Journal of Endocrinology 2014171 389-397. (doi:10.1530/EJE-14-0165)

30 Arafat AM, Möhlig M, Weickert MO, Perschel FH, Purschwitz J, Spranger J, Strasburger CJ, Schöfl C \& Pfeiffer AF. Growth hormone response during oral glucose tolerance test: the impact of assay method on the estimation of reference values in patients with acromegaly and in healthy controls, and the role of gender, age, and body mass index. Journal of Clinical Endocrinology and Metabolism 2008 93 1254-1262. (doi:10.1210/jc.2007-2084)

31 Ghigo E, Aimaretti G, Arvat E \& Camanni F. Growth hormone releasing hormone combined with arginine or growth hormone secretagogues for the diagnosis of growth hormone deficiency in adults. Endocrine 200115 29-38. (doi:10.1385/ENDO:15:1:029)

32 Ho KY, Evans WS, Blizzard RM, Veldhuis JD, Merriam GR, Samojlik E, Furlanetto R, Kaiser DL \& Thorner MO. Effects of sex and age on the 24-hour profile of growth hormone secretion in man: importance of endogenous estradiol concentrations. Journal of Clinical Endocrinology and Metabolism 198764 51-58. (doi:10.1210/jcem-64-1-51)
33 Faria AC, Bekenstein LW, Booth RA Jr, Vaccaro VA, Asplin CM, Veldhuis JD, Thorner MO \& Evans WS. Pulsatile growth hormone release in normal woman during the menstrual cycle. Clinical Endocrinology 199236 591-596. (doi:10.1111/j.1365-2265.1992. tb02270.x)

34 Björk J, Link K \& Erfurth EM. The utility of the growth hormone (GH) releasing hormone-arginine test for diagnosing GH deficiency in adults with childhood acute lymphoblastic leukemia treated with cranial irradiation. Journal of Clinical Endocrinology and Metabolism 200590 6048-6054. (doi:10.1210/jc.2005-0304)

35 Ham JN, Ginsberg JP, Hendell CD \& Moshang T Jr. Growth hormone releasing hormone plus arginine stimulation testing in young adults treated in childhood with cranio-spinal radiation therapy. Clinical Endocrinology 200562 628-632. (doi:10.1111/j.13652265.2005.02272.x)

36 Lissett CA, Saleem S, Rahim A, Brennan BM \& Shalet SM. The impact of irradiation on growth hormone responsiveness to provocative agents is stimulus dependent: results in 161 individuals with radiation damage to the somatotropic axis. Journal of Clinical Endocrinology and Metabolism 200186 663-668. (doi:10.1210/ jcem.86.2.7235)

Received 7 August 2016

Revised version received 24 November 2016

Accepted 8 December 2016 